\title{
O PRINCÍPIO DA MARGEM DE APRECIAÇÃO NACIONAL: EM BUSCA DO TERRENO COMUM
}

\section{EL PRINCIPIO DEL MARGEN DE APRECIACIÓN NACIONAL: BUSCANDO TERRENO COMÚN}

Cláudio Cerqueira Bastos Netto*

Resumo: No presente trabalho, busca-se levantar uma reflexão sobre a aplicação do princípio da margem de apreciação nacional, e expor diferentes posições doutrinárias sobre o tema. Ressalta-se a ligação desse princípio com a subsidiariedade da jurisdição internacional. Após buscar uma definição do princípio e analisar brevemente as jurisprudências do Sistema Europeu de Direitos Humanos e do Sistema Interamericano de Direitos Humanos no tema, são feitas observações sobre a compatibilidade do princípio com as teorias do universalismo e do relativismo cultural dos direitos humanos. Por fim, é feita uma análise crítica do princípio, da necessidade de sua aplicação e de formas de aplicá-lo corretamente.

Resumen: En este trabajo, se intenta empezar una reflexión sobre el principio del margen de apreciación nacional, y exponer diferentes posiciones doctrinarias sobre el tema. Es subrayada la conexión de esta doctrina a la subsidiariedad de la jurisdicción internacional. Después de buscar una definición de la doctrina y analizar brevemente las jurisprudencias del Sistema Europeo de Derechos Humanos y del Sistema Interamericano de Derechos Humanos, se harán observaciones sobre la compatibilidad del principio con las teorías del universalismo y del relativismo cultural de los derechos humanos. Finalmente, se hará un análisis crítico del principio, de la necesidad de su aplicación y de maneras de aplicarlo correctamente.

Palavras-chave: Margem de apreciação nacional, Subsidiariedade, Jurisdição Internacional, Direitos Humanos

Palabras clave: Margen de Apreciación Nacional, Subsidiariedad, Jurisdicción Internacional, Derechos Humanos

\footnotetext{
* Universidade do Estado do Rio de Janeiro, Brasil.

E-mail: cbastosn@gmail.com

Recibido: 23/03/2017. Aceptado: 08/01/2018.
} 


\section{INTRODUÇÃO}

A jurisdição internacional tem a subsidiariedade como uma de suas principais características. O princípio da margem de apreciação nacional está diretamente ligado a tal característica. Ele impõe que o Estado possuirá certa margem para definir o alcance de certos direitos humanos no seu ordenamento interno, desde que os standards internacionais de proteção sejam respeitados. Contudo, surgem problemas na aplicação desse princípio. O quão ampla deve ser a margem concedida ao Estado para que este defina a amplitude de direitos fundamentais, diante do seu contexto político, social, econômico e cultural interno?

Ademais, pode ser questionado se este princípio será usado para que se chancele uma situação de denegação de justiça, no caso de violações de direitos humanos que não sejam sanadas por organismos internacionais sob o fundamento de que o Estado violador dos direitos humanos agiu dentro de sua margem de apreciação nacional. Por outro lado, também pode ser sustentado que o desrespeito à margem de apreciação nacional acarreta em usurpação de competência por parte do organismo internacional que estende sua jurisdição de forma ampla, de modo a alcançar questões que poderiam ser resolvidas de forma satisfatória por autoridades locais.

Ao longo desse trabalho, a importância da margem de apreciação poderá ser percebida nos dispositivos dos tratados internacionais de proteção aos direitos humanos que preveem certa abertura para a ação dos Estados. Também no desafio de limitar corretamente o alcance dos direitos humanos, e na dificuldade de traçar standards mínimos. Analisaremos as jurisprudências do Sistema Europeu de Direitos Humanos e do Sistema Interamericano de Direitos Humanos no tema. Serão citados os casos mais importantes, além da opinião de doutrinadores mais relevantes.

Então, faz-se uma análise crítica do princípio, seus desafios e são expostas opiniões doutrinárias sobre o assunto. Busca-se expor opiniões diversas, a fim de problematizar a questão e, então, propor maneiras de melhorar a aplicação do princípio da margem de apreciação, com o escopo de encontrar um ponto de equilíbrio entre o respeito à subsidiariedade da jurisdição internacional e a efetiva proteção dos direitos humanos.

\section{O QUE É O PRINCÍPIO DA MARGEM DE APRECIAÇÃO NACIONAL?}

A doutrina da margem de apreciação nacional busca conferir limites e determinar os fins da jurisdição internacional. Desenvolvida no Sistema Europeu de Direitos Humanos (doravante SEDH), a doutrina 
sustenta que as autoridades internas, em alguns casos específicos, podem estar em melhor posição para definir as medidas internas necessárias para cumprir um tratado internacional de direitos humanos ${ }^{1}$. Apesar de ser concedido um âmbito de discricionariedade ao Estado, a sua conduta será fiscalizada pelos órgãos internacionais, que determinarão se o Estado agiu de boa fé, respeitou standards mínimos e não impôs condições injustas para o exercício do direito.

Como ensina Manuel Núñez Poblete ${ }^{2}$, esta doutrina admite que, em certos casos, haja uma pluralidade de concepções dos direitos fundamentais, e recomenda que os órgãos jurisdicionais internacionais não assumam o papel de avaliar as circunstâncias que dão base a tais concepções locais de direitos fundamentais, dado que esse é um papel que deve ser exercido pelas autoridades domésticas. $\mathrm{O}$ autor ${ }^{3}$, ao escrever sobre esse princípio, cita a seguinte frase de Montesquieu*: “Acaso no podía consistir la grandeza del genio en saber en qué conviene la uniformidad y en cuál las diferencias?".

Dessa maneira, podemos dizer que os direitos humanos podem estar sujeitos a diferentes limitações, de acordo com uma concepção local específica desse direito. É o caso, por exemplo, da liberdade de expressão, que é um direito reconhecido por toda a comunidade internacional como um direito humano. No entanto, é possível que esse direito seja entendido de forma diferente em países diferentes, por força de aspectos próprios de cada localidade.

Isto pode ser facilmente notado pela maneira que os Estados tratam o discurso de ódio ${ }^{5}$. No Brasil, há julgados do Supremo Tribunal Federal que apresentam uma postura mais repressiva do Judiciário a esse tipo de discurso, enquanto os tribunais estadunidenses tendem a uma defesa quase incondicional da liberdade de expressão. Podemos notar esse contraste comparando o caso Ellwanger, julgado pelo STF, com o caso Nacionalist Socialist Party of America vs. Village of Skokie, julgado pela Suprema Corte do estado de Illinois. No primeiro, o sr. Sigfried Ellwanger foi condenado pelo crime de racismo por ter publicado,

1 GONZÁLEZ, Felipe. "La OEA y los derechos humanos después del advenimiento de los gobiernos civiles: expectativas (in)satisfechas". Revista de derecho: División de Ciencias Jurídicas de la Universidad del Norte, 2001, $\mathrm{n}^{\circ}$ 1, p. 46-47. Disponível em: <http://w1.cejamericas. org/index.php/biblioteca/biblioteca-virtual/doc_view/2723-la-oea-y-los-derechos-humanosdespues-del-advenimiento-de-los-gobiernos-civiles-expectativas-insatisfechas.html>

2 NÚNEZZ POBLETE, Manuel. "Sobre la doctrina de margen de apreciación nacional. La experiencia latinoamericana confrontada y el thelos constitucional de una técnica de adjucación del Derecho Internacional de los Derechos Humanos". En: ACOSTA ALVARADO, P. e NÚÑEZ POBLETE, M. (Ed.). El margen de apreciación en el SIDH: proyecciones regionales y nacionales, México DF: Instituto de Investigaciones Jurídicas, 2012, p. 3.

3 Ibíd., p. 1

4 MONTESQUIEU. El espíritu de las leyes, Libro XXIX, cap. XVIII.

5 Para um estudo mais aprofundado do tema: PORTO MACEDO Jr., Ronaldo. Freedom of Expression: What lessons should we learn from US experience? Disponível em: <https://www. law.yale.edu/system/files/area/center/kamel/sela16_macedo_cv_eng_20160401.pdf> 
vendido e distribuído material antissemita. Nesse caso, entendeu-se que a liberdade de expressão não é absoluta, e foi retraída para proteger a dignidade da pessoa humana. Já no segundo caso, o Partido Nazista foi autorizado a fazer uma passeata numa localidade de maioria de habitantes judeus, usando a suástica como símbolo da liberdade de expressão protegida pela Primeira Emenda à Constituição Americana.

Há grande disparidade na maneira com o que os tribunais agiram para defender a liberdade de expressão nas decisões citadas, e diversas críticas são feitas a ambas as decisões. Exploraremos posteriormente algumas formas de aproximar ideias diferentes, a fim de melhorar a forma a qual interpretamos os direitos humanos. No entanto, podemos dizer que impor uma concepção uniforme desse direito específico a todos os diferentes povos e culturas não parece ideal, senão irrealista. Os direitos humanos não se pretendem ser um bloco monolítico de direitos que não admitem qualquer tipo de abertura a uma interpretação local, baseado em uma teoria universalista radical. Portanto, o princípio da margem de apreciação nacional pode vir a ser utilizado em casos em que as particularidades das concepções locais de direitos humanos precisem ser respeitadas.

Ademais, como veremos posteriormente, esse princípio tem importante relação com a subsidiariedade da jurisdição internacional. A própria ideia de margem de apreciação é sustentada pela referida subsidiariedade no plano jurisdicional internacional, especialmente no caso dos direitos humanos ${ }^{6}$. A subsidiariedade não se confunde com as funções de controle e/ou investigação, desempenhadas por órgãos como a Comissão Interamericana de Direitos Humanos, a ela atribuída pelos instrumentos que a constituem. Observa-se que a subsidiariedade é fundamento de existência dos sistemas regionais de proteção dos direitos humanos, que só reconhecerão a responsabilidade internacional do Estado pela violação de um direito protegido internacionalmente caso a violação não venha a ser sanada na ordem interna, como se nota pela exigência de esgotamento das vias judiciais internas para que uma denúncia seja admissível.

\section{A MARGEM DE APRECIAÇÃO NACIONAL NO SISTEMA EUROPEU DE DIREITOS HUMANOS}

Trata-se de princípio de grande importância para o Sistema Europeu, como se nota pelo Protocolo $n^{\circ} 15$ à Convenção Europeia de Direitos Humanos (doravante $\mathrm{CEDH}$ ), que visa a alterar, inter alia, o preâmbulo do tratado, para incluir em sua redação uma menção ao princípio da subsidiariedade e à margem de apreciação nacional. Observa-se que o Protocolo $\mathrm{n}^{\circ} 15$ só entrará em vigor quando todos

6 NÚÑEZ POBLETE, Manuel. Op. cit., p. 42. 
os Estados partes da CEDH o assinarem e ratificarem, o que ainda não aconteceu ${ }^{7}$. O seu artigo $1^{\circ}$ prevê:

Artigo $1^{\circ}$

No fim do preâmbulo da Convenção, é aditado um novo considerando, cuja redação é a seguinte:

"Afirmando que, em conformidade com o princípio da subsidiariedade, incumbe em primeiro lugar às Altas Partes Contratantes assegurar os direitos e liberdades definidos nesta Convenção e nos respetivos Protocolos, e que ao fazê-lo elas gozam de uma margem de apreciação, sob a supervisão do Tribunal Europeu dos Direitos Humanos criado por esta Convenção,»

O caso Handyside vs. United Kingdom, julgado pela Corte Europeia de Direitos Humanos (doravante Corte EDH) em 1976, é um caso paradigmático, pois aplicou o princípio da margem de apreciação pela primeira vez no Sistema Europeu. Trata-se da censura e apreensão do livro The Little Red Schoolbook, publicado e distribuído no Reino Unido pelo peticionário, o sr. Richard Handyside, editor de livros. Foram aplicadas multas ao sr. Handyside, além do confisco de mais de mil exemplares, sob o argumento de que o livro possuía conteúdo obsceno - a publicação era destinada a jovens, e os estimulava a questionar tabus da sociedade, incluindo capítulos que discutiam temas como sexo e drogas.

Nesse caso, a Corte localizada em Estrasburgo entendeu que a censura imposta ao editor de livros estava consoante com as normas da $\mathrm{CEDH}$, pois foi prescrita por lei e tinha um objeto legítimo. Para tal, invoca-se o artigo 10.2 desse diploma, que dispõe:

ARTIGO $10^{\circ}$

Liberdade de expressão

2. O exercício destas liberdades, porquanto implica deveres e responsabilidades, pode ser submetido a certas formalidades, condições, restrições ou sanções, previstas pela lei, que constituam providências necessárias, numa sociedade democrática, para a segurança nacional, a integridade territorial ou a segurança pública, a defesa da ordem e a prevenção do crime, a proteção da saúde ou da moral, a proteção da honra ou dos direitos de outrem, para impedir a divulgação de informações confidenciais, ou para garantir a autoridade e a imparcialidade do poder judicial.

7 De acordo com consulta realizada em 17 de dezembro de 2017, 38 Estados já ratificaram o Protocolo $\mathrm{N}^{\circ}$ 15. Contudo, estão pendentes as ratificações de: Bélgica, Bósnia e Herzegovina, Croácia, Grécia, Itália, Luxemburgo, Malta, Espanha e Ucrânia. Consulta realizada em: <https://www.coe.int/en/web/conventions/full-list/-/conventions/treaty/213/ signatures?p_auth=ik0yBL1s> 
O dispositivo em questão trata especificamente da liberdade de expressão, e prevê certa de margem para que os Estados limitem o exercício destas liberdades, de acordo com aspectos próprios de suas ordens internas. Na sentença do caso Handyside, a Corte EDH entende de forma majoritária que caberia apenas ao Tribunal de Estrasburgo analisar se os tribunais ingleses não ultrapassaram o alcance imposto pelo dispositivo supra sobre a margem de apreciação concedida aos Estados partes da CEDH, em que pese a posição minoritária de que o julgamento do tribunal doméstico não deveria ser considerado, mas apenas a $\mathrm{CEDH}$ deveria ser usada para avaliar a censura do livro. Isso pode ser notado no trecho a seguirs:

According to the Government and the majority of the Commission, the Court has only to ensure that the English courts acted reasonably, in good faith and within the limits of the margin of appreciation left to the Contracting States by Article 10 para. 2 (art. 10-2). On the other hand, the minority of the Commission sees the Court's task as being not to review the Inner London Quarter Sessions judgment but to examine the Schoolbook directly in the light of the Convention and of nothing but the Convention.

The Court points out that the machinery of protection established by the Convention is subsidiary to the national systems safeguarding human rights (judgment of 23 July 1968 on the merits of the "Belgian Linguistic" case, Series A no. 6, p. 35, para. 10 in fine). The Convention leaves to each Contracting State, in the first place, the task of securing the rights and liberties it enshrines. The institutions created by it make their own contribution to this task but they become involved only through contentious proceedings and once all domestic remedies have been exhausted (Article 26).

Ademais, no trecho supra, ressalta-se que o sistema de proteção aos direitos humanos emanado da $\mathrm{CEDH}$ é subsidiário, de modo que se permite a aplicação do princípio da margem de apreciação. Para tal, apoia-se na máxima de que os Estados partes tem o dever de proteger os direitos humanos, e o sistema europeu só deve agir caso o Estado falhe nesse dever, dada sua subsidiariedade.

De igual forma decide o Tribunal de Estrasburgo no caso James vs. Reino Unido, no qual os peticionários alegam que seu direito à propriedade foi violado pelo Leasehold Reform Act 1967 - lei aprovada pelo Parlamento britânico que permite que locatários adquiram a propriedade do imóvel que vivem de forma compulsória, em nome do benefício público/social. Os peticionários alegam que tal lei não pode

8 Case of Handyside v.The United Kingdom. Application № 5493/72, 7 December 1976, Parágrafo. 47-48 
ser considerada de interesse público, pois concede vantagem apenas a certos indivíduos, em sua esfera privada, a terem acesso à propriedade de um imóvel. A Corte EDH não acolheu esse argumento, e entendeu que a perda do direito de propriedade pode ser utilizada com fins legítimos destinados a benefício público, mesmo que a comunidade como um todo não tenha um uso ou vantagem diretamente obtida por essa perda de propriedade. Ainda, destaca-se:

[b] ecause of their direct knowledge of their society and its needs, the national authorities are in principle better placed than the international judge to appreciate what is "in the public interest". [...] Here, as in other fields to which the safeguards of the Convention extend, the national authorities accordingly enjoy a certain margin of appreciation?

A definição desse limite da atuação estatal pode vir a ser tema de controvérsia entre Estados e a Corte Europeia. Cabe a esta definilo. No caso Dudgeon vs. Reino Unido, por exemplo, a Corte EDH entendeu que era incompatível com a $\mathrm{CEDH}$ a lei penal britânica que criminalizava relações sexuais homossexuais consentidas entre homens adultos na Inglaterra, no País de Gales e na Irlanda do Norte. O Tribunal afirma que as autoridades nacionais podem fazer uma avaliação inicial das circunstâncias sociais de cada caso, e há uma margem de apreciação deixada a elas. No entanto, sua decisão está sujeita à revisão pela Corte $\mathrm{EDH}$, que levará em consideração o objetivo da restrição do direito e a natureza das atividades proibidas para definir o alcance da margem de apreciação.

Assim, nesse caso, entendeu-se que: "[t]he present case concerns a most intimate aspect of private life. Accordingly, there must exist particularly serious reasons before interferences on the part of the public authorities can be legitimate for the purposes of Article 8 (2)" ${ }^{10}$. E assim, o veredito foi de que a referida lei causava interferência injustificada ao direito de respeito à vida privada, previsto no artigo 8 da $\mathrm{CEDH}$ - logo, não se aplicou o princípio da margem de apreciação.

\section{A MARGEM DE APRECIACÃO NACIONAL NO SISTEMA INTERAMERICANO DE DIREITOS HUMANOS}

Assim como o artigo 10.2 da CEDH, alguns dispositivos da Convenção Americana de Direitos Humanos (doravante CADH) dão certa margem para os Estados partes definirem o alcance de alguns direitos na ordem interna. É o que se entende, por exemplo, na Opinião

9 Case James and Others v.The United Kingdom.Application No 8793/79. 21 February 1986. 10 Corte Europeia de Direitos Humanos. Caso Dudgeon vs. Reino Unido. Sentença de 23 de setembro de 1981. Serie A, no 45. Par. 52 
Consultiva $\mathrm{N}^{\circ} 7$, expedida pela Corte Interamericana de Direitos Humanos (doravante Corte IDH) em 1986, sobre o direito de retificação ou resposta, previsto no art. 14.1 da $\mathrm{CADH}$, como se vê no trecho a seguir:

El artículo 14.1 no indica si los afectados tienen derecho a responder en espacio igual o mayor, cuándo debe publicarse la respuesta una vez recibida, en qué lapso puede ejercerse el derecho, qué terminología es admisible, etc. De acuerdo con el artículo 14.1, estas condiciones serán las "que establezca la ley", frase que implica un lenguaje que, a diferencia del utilizado en otros artículos de la Convención ("estará protegido por la ley", "conforme a la ley", "expresamente fijadas por ley", etc.), requiere el establecimiento de las condiciones para el ejercicio del derecho de rectificación o respuesta por medio de la "ley", cuyo contenido podrá variar de un Estado a otro, dentro de ciertos límites razonables y en el marco de los conceptos afirmados por la Corte. ${ }^{11}$ (grifo acrescentado)

Nota-se que, ao dar tal opinião, a Corte não menciona o conceito de margem de apreciação nacional. Contudo, a interpretação concedida admite que condições para o exercício do direito sejam definidas na ordem interna, e podem variar entre Estados diferentes. Eis a manifestação da subsidiariedade da jurisdição internacional.

Curiosamente, em ocasião anterior, a Corte IDH usa o conceito de margem de apreciação para conceder sua opinião. Isso ocorreu na Opinião Consultiva $\mathrm{N}^{\circ}$ 4, sobre a interpretação do artigo 20 da CADH, que garante o direito à nacionalidade. Foi solicitada pela Costa Rica, que questionava se seu projeto reforma constitucional que alterava os dispositivos sobre naturalização estava de acordo com a CADH. Entendeu-se que o Estado está autorizado a estabelecer os requisitos para aquisição da nacionalidade. No entanto, é necessário que se observe a igualdade perante a lei e a não discriminação, que estão previstas no art. 1 (1) e 24, do Pacto de San José. Assim entende o Tribunal:

Esa conclusión de la Corte tiene especialmente en cuenta el margen de apreciación reservado al Estado que otorga la nacionalización sobre los requisitos y conclusiones que deben llenarse para obtenerla. Pero de ningún modo podría verse en ella una aprobación a la tendencia existente en algunas partes a restringir exagerada e injustificadamente el ámbito de ejercicio de los derechos políticos de los naturalizados. La mayoría de estas hipótesis, no sometidas por cierto a la consideración de la Corte, constituyen verdaderos casos de discriminación en razón del origen o del lugar de nacimiento que crean injustamente dos grupos

11 Corte IDH. Opinião Consultiva $\mathrm{N}^{\circ}$ 7. Publicada em 29 de agosto de 1986. Serie A, $\mathrm{n}^{\circ} 7$. Parágrafo 27 
de distintas jerarquías entre nacionales de un mismo país ${ }^{12}$. (grifo acrescentado)

A aplicação do princípio também está presente na Comissão IDH. Isso se nota, por exemplo, em casos sobre participação política, especialmente na interpretação do artigo 23 da CADH. Assim ocorreu no caso José Efraín Ríos Montt vs. Guatemala ${ }^{13}$. Trata-se de denúncia submetida à $\mathrm{CIDH}$ pelo ex-presidente de facto da Guatemala, que governou o país entre 1982 e 1983, período no qual foi suspensa a vigência da Constituição guatemalteca. Ele alega que foram violados seus direitos protegidos pela CADH, em seus artigos 8 (garantias judiciais), 25 (proteção judicial), e 32 (imparcialidade na administração da justiça), em razão dos atos de autoridades públicas guatemaltecas que declararam inadmissível sua candidatura à presidência da referida república. Tal inadmissibilidade foi baseada no artigo 186.a da Constituição política então vigente na Guatemala, que disciplinava a eleição presidencial e tinha a seguinte redação:

[N]o podrán optar a ese cargo,

a. El caudillo ni los jefes de un golpe de Estado, revolución armada o movimiento similar, que haya alterado el orden constitucional, ni quienes como consecuencia de tales hechos asuman la Jefatura de Gobierno...

A CIDH, ao examinar a admissibilidade da denúncia submetida por Ríos Montt ao SIDH, entende que a disposição da Constituição guatemalteca não vulnera qualquer direito protegido pela $\mathrm{CADH}$, levando em conta que a referida restrição ao direito se insere dentro de um contexto não-discriminatório, no qual se aplica a margem de apreciação:

[...] considera la Comisión que el contexto del derecho constitucional guatemalteco e internacional en que se ubica esta condición de inelegibilidad es la dimensión apropiada para el análisis de la aplicabilidad de la Convención en general, y de sus artículos 23 y 32 al caso sub-judice, y de la cual puede surgir el margen de apreciación permitido por el derecho internacional ${ }^{14}$. (grifo acrescentado)

12 Corte IDH. Opinião Consultiva n ${ }^{\circ}$ 4. Expedida em 19 de janeiro de 1984. Serie A, N 4 . Parágrafo 62.

13 Comissão Interamericana de Direitos Humanos, Relatório nº. 30/93, caso no. 10.804, José Efraín Montt vs. Guatemala, 12 de outubro de 1993, parágrafo 24, disponível em http://www. cidh.oas.org/annualrep/93span/cap.III.guatemala10.804.htm, acesso em 22/03/2017.

14 Ibíd., \$24. 
Nesse caso, cita-se o artigo $32 \mathrm{da} \mathrm{CADH}$, que trata dos direitos e deveres, e, inter alia, dispõe: "Os direitos de cada pessoa são limitados pelos direitos dos demais, pela segurança de todos e pelas justas exigências do bem comum, em uma sociedade democrática". Nesse ponto, cabe ressaltar que não há nenhum dispositivo do Pacto de San José que preveja expressamente a aplicação do princípio da margem de apreciação, mas a discussão sobre a melhor posição dos órgãos nacionais fez parte de seus trabalhos preparatórios. Sobre o tema, Núñez Poblete ${ }^{15}$ destaca:

En este último ámbito hay que recordar que, la "mejor posición" de los órganos nacionales para pronunciarse sobre el alcance de ciertos derechos, si bien no fue explicitada en el texto del Pacto de San José, atravesó parte de los trabajos preparatorios de dicho instrumento, lo que hace pensar que en algún sentido ella estuvo en la mente de los representantes. (grifo acrescentado)

$\mathrm{O}$ autor também ressalta que a própria Corte IDH afirma que a “jurisdição internacional é subsidiária e complementária”"16. Ademais, aponta, de forma não exaustiva, seis áreas nas quais se aplicou de alguma forma a doutrina aqui estudada, sendo essas:

a) el desarrollo normativo interno de los derechos reconocidos en la $\mathrm{CADH}$; b) la configuración de las instituciones nacionales que inciden en el desarrollo o ejercicio de los derechos reconocidos en la Convención; d) la valoración de las circunstancias materiales que justifican la limitación de los derechos reconocidos en la Convención; d) la regulación de los derechos no reconocidos en la Convención; e) el alcance de la jurisdicción de la Corte IDH en los casos contenciosos; y f) el cumplimiento de las sentencias de la Corte IDH. ${ }^{17}$

No entanto, há um número muito menor de casos nos quais se aplicou o princípio da margem de apreciação no SIDH quando comparado com o SEDH. Por outro lado, podemos ver que esse princípio

15 NÚÑEZ POBLETE, Manuel, Op. cit., p. 41-42.

16 Ibíd., p. 43. São apontados como precedentes nesse sentido: Corte IDH. Caso Perozoy otros vs. Venezuela, sentencia del 28 de enero de 2009 (excepciones preliminares, fondo, reparaciones y costas), párr. 64, notas marginales omitidas. De acordo com Núñez Poblete: "La Corte se remite a la jurisprudencia sobre subsidiariedad de los casos Acevedo Jaramillo y otros vs. Perú, sentencia del 24 de noviembre de 2006 (interpretación de la sentencia de excepciones preliminares, fondo, reparaciones y costas), párr. 66, y Zambrano Vélez y otros vs. Ecuador, sentencia del 4 de julio de 2007 (fondo, reparaciones y costas), párr. 47. El carácter complementario aparece en esta sentencia fundamentado en el Preámbulo de la CADH y también en las opiniones consultivas OC-2/82, 24 de septiembre de 1982, párr.31; OC-6/86 9 de mayo de 1986, párr.26; y el caso Velásquez Rodríguez vs. Honduras, sentencia del 29 de julio de 1988 (fondo), párr.61."

17 NÚÑEZ POBLETE, Manuel, Op. cit., p. 22-23. 
não está inteiramente ausente do SIDH, como afirmam alguns autores ${ }^{18}$.

\section{ANÁLISE CRÍTICA}

\subsection{O problema da demasiadamente ampla margem de apreciação nacional}

Apesar de gozar de apoio de expressiva parte da comunidade acadêmica, a aplicação do princípio também sofre críticas. Uma dessas é a observação de Eyal Benvenisti ${ }^{19}$, que critica a adoção dessa doutrina pela Corte EDH, e aponta que esta desenvolveu uma teoria do consenso mínimo para determinar o alcance da margem de apreciação. $\mathrm{O}$ autor explica:

The adjudicating organ must either adopt a moral standard or defer to a relativisticapproach based on a comparative analysis. The ECHR has opted for the latter approach by developing the doctrine of consensus. This doctrine, coupled with the margins doctrine,poses another serious obstacle to the international protection of minority values. In the jurisprudence of the ECHR, consensus is inversely related to the margins doctrine: the less thecourt is able to identify a European-wide consensus on the treatment of a particular issue, the wider the margins the court is prepared to grant to the national institutions. Minority values, hardly reflected in national policies, are the main losers in this approach. ${ }^{20}$ (grifo acrescentado)

Como consta no trecho grifado, Benvenisti ressalta que minorias ou grupos vulneráveis ${ }^{21}$ podem ser os mais prejudicados. O autor afirma que a Corte deixa de cumprir seu papel de guardiã externo contra a tirania das maiorias ${ }^{22}$. Afinal, muitos conjuntos de minorias, que podem ser grupos étnicos, nacionais ou religiosos que são numericamente

18 CONTESSE, Jorge. "Subsidiarity in inter-American human rights law", p. 20. Trabalho apresentado no Seminar in Latin America on Constitutional and Political Theory (SELA) 2015. Disponível em: <https://www.law.yale.edu/system/files/documents/pdf/SELA15_Contesse_ CV_Eng.pdf >

19 BENVENISTI, Eyal. "Margin of Apreciation, Consensus, and Universal Standards”. New York University Journal of International Law and Politics. 1998, n 31, p. 843-854.

20 Ibíd., p. 851.

21 Benvenisti usa o termo 'minorias'. No entanto, acreditamos que a nomenclatura 'grupos vulneráveis' é mais acertada, já que alguns grupos podem estar, dentro do contexto de uma sociedade, em situação de vulnerabilidade, mas não serem uma minoria numérica em relação a demais grupos. É o caso, por exemplo, das mulheres, que, mesmo estando em paridade numérica com os homens, podem vir a estar em situação de vulnerabilidade em uma sociedade, além de não estarem devidamente representadas no poder público. Isso pode ser notado, no contexto brasileiro, na baixa representação de mulheres na política. Apesar de já ter tido uma mulher presidente, nas eleições de 2014, a percentagem de mulheres entre os parlamentares eleitos ao Congresso Nacional foi de apenas $10 \%$.

22 BENVENISTI, Eyal, Op. cit., p. 852. 
inferiores à maioria e/ou estão em condição de vulnerabilidade, podem vir a ser pouco representados ou até mesmo perseguidos no contexto político nacional. Caso os poderes públicos, na ordem interna desses Estados, falhem em proteger os direitos de tais minorias, a jurisdição internacional será o último recurso disponível para que essas pessoas busquem a proteção de seus direitos humanos, e talvez a única opção para obter reparação em caso de direitos violados ${ }^{23}$.

Paolo Carozza ${ }^{24}$ ao criticar a teoria do consenso mínimo, aplicada no SEDH, aponta: "Surely the Convention did not mean to efface all national differences in the name of uniformity, but instead to set a minimum level of compatibility". Assim, o autor rejeita um universalismo radical, e admite que haja certa abertura para a ação dos Estados partes da CEDH na ordem interna. Contudo, a Convenção deve estabelecer padrões mínimos de compatibilidade. Não é necessário que a Corte EDH sempre busque um consenso entre os demais Estados para definir o conteúdo de um direito. Afinal, essa prática seria um desserviço à primeira convenção concebida como instrumento internacional vinculante aos Estados partes e gerador de obrigações internacionais de proteção dos direitos humanos dos indivíduos sujeitos às suas jurisdições.

O eminente jurista Antônio Augusto Cançado Trindade critica a proposta de adoção do princípio na margem de apreciação no sistema interamericano, e questiona:

How could we apply [the margin of appreciation doctrine] in the context of a regional human rights system where many countries' judges are subject to intimidation and pressure? How could we apply it in a region where the judicial function does not distinguish between military jurisdiction and ordinary jurisdiction? How could we apply it in the context of national legal systems that are heavily questioned for the failure to combat impunity? ... We have no alternative but to strengthen the international mechanisms for protection ... Fortunately, such doctrine has not been developed within the inter-American human rights system ${ }^{25}$.

De certo modo, à crítica do ex-juiz da Corte IDH assiste razão. Podemos tomar como exemplo os casos julgados contra Honduras, nos quais a aplicação dessa doutrina foi um dos argumentos de defesa do

23 Ibíd., p. 848.

CAROZZA. Paolo G. "Uses and Misuses of Comparative Law in International Human Rights: Some Reflections on the Jurisprudence of the European Court of Human Rights". Notre Dame . Rev. 1998, p. 1217-1238.

25 CANÇADO TRINDADE, Antônio Augusto. El Derecho Internacional de los Derechos Humanos en el Siglo XXI. 2008, 390. 
Estado. Como aponta Jimena Bonilla Cabañas ${ }^{26}$, tais casos tratam de flagrantes violações de direitos humanos, como execuções extrajudiciais, detenções ilegais, suposta falta de celeridade em investigações ou negligência de autoridades judiciais. "Por lo tanto, ninguno de los casos contenciosos resueltos hasta ahora por la Corte IDH ha implicado diferencias de interpretación jurídica entre el ordenamiento jurídico interno hondureño y la Corte IDH" ${ }^{27}$, conclui a jurista. Dessa maneira, devemos levar em consideração a realidade dos Estados partes da $\mathrm{CADH}$, dada a gravidade das violações de direitos humanos ocorridas no continente, se comparadas com os casos do Sistema Europeu.

Na mesma linha, Felipe González ${ }^{28}$, um dos atuais comissários da Comissão Interamericana de Direitos Humanos, afirma que a doutrina é criticada mesmo por especialistas no SEDH, e que este a aplica de forma errática e imprevisível. Também afirma que os limites do poder discricionário do Estado não são estão absolutamente definidos no SEDH, pois este já aplicou um standard europeu comum a todos os Estados em vez de aplicar essa doutrina.

Por outro lado, outros doutrinadores possuem opinião divergente. Jorge Contesse ${ }^{29}$ classifica como expansiva a postura da Corte IDH, e acredita que o referido princípio deveria ser adotado. Contesse afirma que o posicionamento de Cançado Trindade faria sentido no fim dos anos 80, quando eram julgados casos de graves violações de direitos humanos cometidas por Estados autoritários. Hoje, depois de duas décadas de evolução da jurisprudência e do surgimento de democracias nestes Estados que passaram por regimes ditatoriais, poderia ser adotada uma posição mais moderada, segundo o jurista.

Pode-se dizer que Contesse e Cançado Trindade têm opiniões divergentes por terem percepções diferentes da realidade do continente nos dias de hoje. É verdade que houve uma transição de regimes autoritários para regimes democráticos em vários dos Estados partes nas últimas décadas, como destaca Contesse. No entanto, nota-se que graves violações de direitos humanos ainda são denunciadas ao sistema interamericano até os dias de hoje $\mathrm{e}^{30}$.

26 BONILLA CABAÑAS, Jimena. "Casos Hondureños ante el Sistema Interamericano y el uso de la doctrina del margen de apreciación”. En: ACOSTA ALVARADO, P. e NÚÑEZ POBLETE, M. (Ed.) El margen de apreciación en el SIDH: proyecciones regionales y nacionales, México DF: Instituto de Investigaciones Jurídicas, 2012, p. 271-284. Disponível em: <http:// biblio.juridicas.unam.mx/libros/7/3160/13.pdf>

27 Ibíd., p. 279.

28 GONZÁLEZ, Felipe. Op. cit., p. 47.

29 CONTESSE, Jorge (2015). Op. cit. p. 17.

30 Dois casos recentemente julgados pela Corte IDH contra o Estado brasileiro são bons exemplos, sendo esses: o caso Trabalhadores da Fazenda Brasil Verde vs. Brasil, no qual foi denunciada a manutenção de pessoas em situação análoga à escravidão em uma fazenda no estado do Pará, além do desaparecimento de duas dessas; e o caso Favela Nova Brasília, que trata de um caso de violência policial numa favela do Rio de Janeiro que envolve execuçôes sumárias e estupros de moradores da localidade. 


\subsection{Margem de apreciação e relativismo cultural}

O jurista Roberto Gargarella critica a postura da Corte IDH no caso Gelman vs. Uruguai, no qual este país foi condenado pelo desaparecimento forçado de María Claudia de Gelman e o sequestro de sua filha Macarena Gelman durante a ditadura militar uruguaia. $\mathrm{Na}$ sentença, condenou-se o país a remover todos os obstáculos que permitissem a impunidade daqueles responsáveis pelos referidos crimes. Ainda, declarou-se que a lei de anistia uruguaia, que proíbe a persecução penal de indivíduos que cometeram graves violações de direitos humanos, era incompatível com a CADH e a Convenção Interamericana sobre Desaparecimento Forçado de Pessoas, sendo, portanto, sem efeito legal.

$\mathrm{O}$ autor ressalta que a referida lei uruguaia foi aprovada democraticamente em 1986, e teve sua validade confirmada por referendo em duas ocasiões diferentes, nas quais a população do Uruguai decidiu manter a vigência da lei de anistia. Contudo, de acordo com o posicionamento da Corte IDH, as leis de anistia são expressamente incompatíveis com a CADH e seu espírito, por impedirem a persecução penal dos responsáveis por graves violações de direitos humanos. Assim se entendeu nos casos Barrios Altos vs. Peru, La Cantuta vs. Peru, Almonacid Arellano vs. Chile, e Gomes Lund vs. Brasil.

Gargarella afirma que as leis de anistia de cada país guardam um grau de legitimidade democrática diferente, e a Corte IDH falha ao não considerar as nuances de cada uma destas. Nos casos da Argentina e do Peru, há ausência de legitimidade democrática das referidas leis, dado que foram impostas por regimes ditatoriais, em seu próprio favor. A lei de anistia uruguaia de fato possui maior grau de legitimidade quando comparada com as demais leis que foram objeto dos casos supra citados, por ter sido aprovada pelo voto popular em dois referendos.

O jurista argentino então afirma que a Corte IDH deveria ao menos ter elaborado um esforço argumentativo diferenciado, dadas as diferenças do caso Gelman em relação aos demais casos. Contudo, a Corte entendeu que o processo de adoção da lei era irrelevante, pois é incompatível com a CADH sua ratio legis, ou seja, a manutenção de impunidade a graves violações de direitos humanos ${ }^{31}$.

Ao analisar o caso em questão e a opinião de Gargarella, diferentes posturas quanto à decisão da Corte IDH podem ser tomadas. No entanto, nosso objetivo ao levantar este debate é mostrar que o princípio da margem de apreciação não dá abertura apenas a questões culturais próprias de certa comunidade.

No caso da lei de anistia uruguaia, por exemplo, os que defendem

31 Corte IDH. Caso Gelman vs. Uruguai. Sentença de 24 de fevereiro de 2011 (Mérito, Reparação e Julgamento). Série C, N²21, para. 229. 
a aplicação do princípio da margem de apreciação não o fazem porque existem características culturais exclusivas do Estado uruguaio em relação aos demais países latino-americanos, mas pelo processo político-democrático ocorrido naquele país que manteve a vigência da lei de anistia. A teoria do relativismo cultural é incompleta, já que desconsidera o fato de a construção dos direitos humanos não levar em conta apenas aspectos culturais, mas também a realidade econômica, social e política de uma sociedade.

\subsection{O respeito à diversidade na jurisdição internacional: em busca do terreno comum}

As relações entre subsidiariedade e direitos humanos são muito importantes e não podem ser deixadas de lado na busca de um direito internacional que proteja a dignidade da pessoa humana e a diversidade da sociedade humana simultaneamente. Como leciona Paolo Carozza, pode ser feito uso do direito comparado para identificar uma tradição legal que dá origem aos standards internacionais de direitos humanos, que não são um conjunto de normas desvinculados ou sem contexto ${ }^{32}$. Por outro lado, as comparações podem servir para se buscar um entendimento mais universalizado de normas abrangentes de direitos humanos ao se questionar suas similaridades dentre as diferentes culturas.

Dessa maneira, o ideal é buscar terreno comum entre as posições divergentes. Não se deve adotar um modelo bottom-up, como propõe Contesse $^{33}$, pois esse modelo reduz drasticamente o papel dos mecanismos internacionais de proteção dos direitos humanos, o que pode causar prejuízos ao indivíduo, especialmente no caso de proteção de minorias e grupos vulneráveis, como foi exposto anteriormente.

Por outro lado, o unilateralismo internacionalista não parece o melhor modelo a ser adotado. É necessário que haja diálogo entre os órgãos internacionais e as autoridades nacionais, o que não exclui a capacidade daquelas de impor standards mínimos de proteção a estas, além de analisar sua conduta.

Nesse ponto, deve ser levada em consideração a observação de Anne-Marie Slaughter, que prescreve a existência de uma comunidade global de cortes. Para a jurista, houve uma transição de dois sistemas jurídicos diferentes (internacional e doméstico) para apenas um. Em suas próprias palavras:

The underlying conceptual shift is from two systems-international

32 CAROZZA, Paolo. Op. cit., p. 1236.

33 CONTESSE, Jorge. "The final word? Constitutional dialogue and the Inter-American

Court of Human Rights". International Journal of Constitutional Law (forthcoming 2016)

Disponível em: <http://papers.ssrn.com/sol3/papers.cfm?abstract_id=2795312> 
and domestic-to one; from international and national judges to judges applying international law, national law, or a mixture of both. In other words, the institutional identity of all these courts, and the professional identity of the judges who sit on them, is forged more by their common function of resolving disputes under rules of law than by the differences in the law they apply and the parties before them. It stretches too far to describe them all as part of one global legal system, but they certainly constitute a global community of courts ${ }^{34}$.

A tese de Slaughter se insere no contexto de novas teorias, que deixam para trás o debate entre monismo e dualismo, e passam a enxergar um pluralismo de ordens jurídicas. É o que desenvolve Mireille Delmas-Marty, em sua obra "Por um direito comum", na qual defende a harmonização entre diferentes ordens jurídicas. A francesa afirma ser necessária buscar uma integração que visa a estabelecer um direito comum a todos, em detrimento da submissão de uma à outra ${ }^{35}$. Ela questiona o modelo kelseniano, afirmando que se trata de uma pirâmide inacabada:

Por mais tranquilizante que seja, a metáfora da pirâmide dificilmente dá conta da paisagem observada.

Pouco compatível, por sua própria permanência, com a instabilidade do tempo normativo, ela também não se adapta à heterogeneidade espacial: onde colocar as normas internacionais em relação às normas constitucionais? E coo situar, umas relativamente às outras, as normas do direito comunitário e as da Convenção Europeia de Direitos do Homem? [...]

Se pirâmide há, impõem-se o plural e o matiz: é de "pirâmide inacabada" que conviria falar. Resta a dificuldade, praticamente insuperável, de colocar nessa - ou nessas - hierarquia(s) normativa(s) os princípios gerais do direito que foram descritos a um só tempo fora do sistema como o direito natural e integrados a ele, pois de direito positivo; de direito interno e de direito internacional; escritos e não escritos; superiores e iguais às leis. E, finalmente, ao mesmo tempo iguais e desiguais entre si. [...] Em resumo, poderíamos dizer que, se o plano de composição se embaralhou, não é porque tenha desaparecido toda hierarquia, mas porque mudou o desenho. Em vez de hierarquia contínua e linear que a imagem da pirâmide expressava, aparecem hierarquias descontínuas, como outras tantas pirâmides inacabadas e hierarquias enredadas que formam "anéis estranhos", retomando a imagem de Hofstadter. ${ }^{36}$

34 SLAUGHTER, Anne-Marie. “A Global Community of Courts”. Harvard International Law Journal,. 2003, vol 44, $\mathrm{n}^{\circ}$ 1, p. 191- 219.

35 DELMAS-MARTY, Mireille. Por um direito comum. Tradução Maria Ermantina de Almeida Prado Galvão. São Paulo : Martins Fontes, 2004.

36 Ibíd., p. 86-87 
Assemelha-se à teoria dos autores belgas François Ost e Michel Van De Kerchove, que defendem que a alegoria da pirâmide kelseniana foi transformada, e a forma atual de se produzir o Direito mais se assemelha a uma pirâmide. Em vez de subordinação da ordem interna à ordem internacional, ou vice-versa, note-se que há certa coordenação e coexistência entre as diferentes ordens jurídicas. Não persiste a ideia de subordinação e linearidade entre diferentes ordens jurídicas, como defendeu Kelsen ${ }^{37}$.

$\mathrm{Na}$ mesma linha, Rafael Bustos Gisbert desenvolve uma teoria da liga de constituições ou rede de constituições ${ }^{38}$. A teoria do jurista espanhol ressalta que não há hierarquia entre essas distintas constituições, e, no caso do ordenamento jurídico espanhol, indica que há três lugares constitucionais dentro de sua rede: a Constituição espanhola, as normas provenientes da União Europeia e as normas provenientes do Conselho da Europa. Gisbert rejeita a terminologia 'constitucionalismo multinível', utilizada por Ingolf Pernice ${ }^{39}$, por entender que o uso de níveis remete a uma estrutura hierárquica, e sua ideia não é a de estabelecer níveis territoriais homogêneos.

A teoria do autor descreve uma rede de constituições incompletas, que é reflexo de um cenário de pluralismo constitucional, que não possui hierarquia entre as distintas constituições. Cada ponto da rede representa um lugar metaconstitucional com sua correspondente metaconstituição.

Para ilustrar seu exemplo, o autor ressalta que a UE não está sujeita às normas do Conselho da Europa, nem deve se submeter à jurisdição da Corte EDH. Contudo, existe interação entre ambas as ordens, com o interesse de um enriquecimento mútuo.

Debe notarse que las relaciones entre los diferentes lugares metaconstitucionales tendrán diferente intensidad y naturaleza. [...] [L]as formas de relación son variables y denotan interacciones más o menos poderosas en función del grado de reconocimiento de las metaconstituciones entre sí. Formas de relación que a menudo no son jurídico-formales, pero no por ello dejan de ser igualmente eficaces y condicionantes del propio discurso constitucional. Así, no es extraño comprobar cómo determinados contenidos constitucionales desarrollados en un lugar metaconstitucional supranacional están condicionados por los actos de otro del que no son, formalmente,

37 KELSEN, Hans. "As relações de sistema entre o direito interno e o direito internacional público”. Revista de Direito Internacional, 2011, vol 8, nº 2011.

38 GISBERT, Rafael Bustos. "Elementos constitucionales en la red global". Estudios de Deusto, 2012, vol 60, n 2 , p. 21-44.

39 Utilizada por: PERNICE, I. Multilevel Constitutionalism and the Treaty of Amsterdam: European Constitution Making revisited? In.: Common Market Law Review, 36, 1999. Apud GISBERT, Rafael Bustos, Op. cit. 
parte. Así, por ejemplo, es habitual que el TEDH se apoye en el Alto Comisionado de Naciones Unidas contra la tortura a la hora de establecer si la extradición de un extranjero detenido en alguno de los Estados miembros es o no conforme con la prohibición de tratos inhumanos o degradantes ${ }^{40}$.

Nesse contexto, é relevante a observação de Slaughter, que afirma existir, nos dias de hoje, um fenômeno que chama de "constitutional cross-fertilization", no qual os tribunais domésticos de diferentes países citam uns aos outros, usando as decisões estrangeiras não como precedentes vinculantes, mas como autoridade persuasiva. O uso dessa autoridade persuasiva pode ser útil para que os juízes possam proferir decisões melhores. Nesse ponto, Slaughter cita um voto do juiz da Suprema Corte Americana Stephen Breyer, que afirma que a experiência de outras Cortes: "cast an empirical light on the consequences of different solutions to a common legal problem" 41 .

$\mathrm{Na}$ mesma linha, a juíza Ruth Bader Grinsburg, também da Suprema Corte Americana, afirma que problemas como discriminação e preconceito são fenômenos globais, e todas as sociedades podem aprender umas com as outras sobre soluções para tais problemas. Dessa maneira, olhar para o direito comparado ajuda os juízes a cumprir o seu trabalho de forma melhor no âmbito doméstico. Slaughter justifica: "Foreign authority is persuasive because it teaches them something they did not know or helps them see an issue in a different and more tractable light"42.

Portanto, o diálogo entre as cortes pode ser benéfico para a construção de melhores decisões judiciais, especialmente em casos de difícil solução, como são os casos sobre liberdade de expressão citados anteriormente. Esta interação deve ser usada pelos juízes não só no âmbito interno, mas também na esfera internacional, a fim de garantir uma tutela de excelência dos direitos humanos, e que possam ser traçados standards mínimos de maior qualidade, evitando a aplicação errática e irregular do princípio da margem de apreciação nacional.

$\mathrm{O}$ princípio da integridade desenvolvido por Ronald Dworkin ${ }^{43}$ também pode ser levado em consideração para avaliar se a conduta do Estado está dentro dos standards mínimos de proteção. Podemos definir a integridade da seguinte forma:

A integridade é uma terceira virtude política, ao lado da justiça e do devido processo legal, a qual se refere ao compromisso de que o governo aja de modo coerente e fundamentado em princípios com todos os seus

40 Ibidem.

41 SLAUGHTER, Op. cit., p. 200

42 SLAUGHTER, Op. cit., p. 201

43 DWORKIN, Ronald. O império do Direito. (Trad. de Jefferson Ruiz Camargo). $2^{\text {a }}$ ed. São Paulo: Martins Fontes, 2007. 
cidadãos, a fim de estender a cada um os padrões fundamentais de justiça e equidade ${ }^{44}$.

Ainda, nas palavras de Ronald Dworkin:

A integridade detém seu olhar sobre essas questões de principio: o governo deve ter uma só voz ao se manifestar sobre a natureza desses direitos, sem negá-los, portanto, a nenhuma pessoa em momento algum. $\mathrm{O}$ efeito da integridade sobre as decisões políticas é mais difuso. Exige, como afirmei, que o governo persiga alguma concepção coerente daquilo que significa tratar as pessoas como iguais, mas esta é, sobretudo, uma questão de estratégias gerais e de testes estatístico preliminares. Quanto ao mais, não exige uma coerência limitada no âmbito das politicas: não exige que programas específicos tratem todos da mesma maneira. Contudo, o interesse da integridade pelos direitos e princípios às vezes desqualifica um certo tipo específico de incoerência. Uma legislatura norte-americana não poderia decidir que nenhum agricultor católico recebesse subsídios mesmo que, inacreditavelmente, houvesse sólidas razões políticas para tal discriminação ${ }^{45}$.

Assim, o respeito ao princípio da integridade poderia ser usado pelos organismos internacionais para avaliar se a conduta do Estado está descumprindo os deveres de proteção estabelecidos no direito internacional. Afinal, a integridade impõe obrigação de tratar as pessoas com coerência, e define alguns tipos de incoerências permitidas, mas sempre o faz com o fim de garantir que o Estado cumpra com seu dever de tratar as pessoas de forma igual. Nota-se que o direito a igual proteção da lei é bem estabelecido na ordem internacional, e está previsto no artigo VII na Declaração Universal dos Direitos Humanos, proclamada em 1948.

\section{CONCLUSÃO}

Nota-se que tanto a visão universalista radical quanto o relativismo cultural falharam em estabelecer uma concepção ideal de direitos humanos. Não pretendemos aprofundarmos neste debate, mas apenas tomar uma visão moderada, e evidenciar a necessidade de buscar um ponto de equilíbrio entre as teorias que dê ensejo à aplicação adequada do princípio da margem de apreciação nacional.

Podemos perceber que há diferentes concepções do princípio da

44 FERRI, Carolina F. Sarraf. “Teoria da integridade: Uma abordagem da sistematização de Ronald Dworkin". Disponível em: <http://www.ambito-juridico.com.br/ site/?n_link=revista_artigos_leitura\&artigo_id=13123>

45 DWORKIN, Ronald, Op. cit., p. 268 
margem de apreciação. Buscar uma concepção idêntica dos direitos humanos, com base em um universalismo radical, não parece ser a postura mais adequada. Por outro lado, como mostra a crítica de Benvenisti, uma abertura demasiada ao Estado pode gerar prejuízo à proteção dos direitos humanos, especialmente no caso de proteção de minorias.

A fim de evitarqueviolações de direitoshumanos ocorram, devemos buscar o cumprimento do direito internacional em sua totalidade, de forma efetiva e de boa-fé. Ao mesmo tempo, deve haver diálogo entre as esferas doméstica e internacional, a fim de evitar o unilateralismo de qualquer uma das partes, e que certa margem de atuação do Estado seja respeitada. Para alcançar esse objetivo, deve-se buscar uma via di mezzo, um ponto de equilíbrio no qual a subsidiariedade da jurisdição internacional seja respeitada e, concomitantemente, o princípio da margem de apreciação não seja tão amplo que venha a potencialmente diminuir a proteção ao indivíduo.

Em busca de melhoras a essa doutrina, propomos o diálogo entre cortes, a fim de melhorar a qualidade das decisões dos tribunais nacionais e internacionais, através da autoridade persuasiva encontrada no direito comparado. Ademais, princípios como a integridade de Dworkin também podem ser ferramentas úteis na construção de um modelo de interação melhor entre as esferas nacional e internacional.

\section{REFERÊNCIAS BIBLIOGRÁFICAS}

BENVENISTI, Eyal. "Margin of Apreciation, Consensus, and Universal Standards". New York University Journal of International Law and Politics. 1998, n 31, p. 843-854.

BONILLA CABAÑAS, Jimena. "Casos Hondureños ante el Sistema Interamericano y el uso de la doctrina del margen de apreciación”. En: ACOSTA ALVARADO, P. e NÚÑEZ POBLETE, M. (Ed.) El margen de apreciación en el SIDH: proyecciones regionales y nacionales, México DF: Instituto de Investigaciones Jurídicas, 2012, p. 271-284. Disponível em: <http://biblio.juridicas.unam.mx/libros/7/3160/13.pdf>

CANÇADO TRINDADE, Antônio Augusto. El Derecho Internacional de los Derechos Humanos en el Siglo XXI. 2008, 390.

CAROZZA. Paolo G. "Uses and Misuses of Comparative Law in International Human Rights: Some Reflections on the Jurisprudence of the European Court of Human Rights". Notre Dame. Rev. 1998, p. 12171238 .

CONTESSE, Jorge. "Subsidiarity in inter-American human rights law". Trabalho apresentado no Seminar in Latin America on Constitutional and 
Political Theory (SELA), 2015. Disponível em <https:/www.law.yale. edu/system/files/documents/pdf/SELA15_Contesse_CV_Eng.pdf>

CONTESSE, Jorge. "The final word? Constitutional dialogue and the Inter-American Court of Human Rights". International Journal of Constitutional Law (forthcoming 2016) Disponível em: <http://papers. ssrn.com/sol3/papers.cfm?abstract_id=2795312>

DELMAS-MARTY, Mireille. Por um direito comum. Tradução Maria Ermantina de Almeida Prado Galvão. São Paulo : Martins Fontes, 2004.

DWORKIN, Ronald. O império do Direito. (Trad. de Jefferson Ruiz Camargo). $2^{\text {a }}$ ed. São Paulo: Martins Fontes, 2007.

FERRI, Carolina F. Sarraf. "Teoria da integridade: Uma abordagem da sistematização de Ronald Dworkin”. Disponível em: <http://www. ambito-juridico.com.br/site/?n_link=revista_artigos_leitura\&artigo_ id $=13123>$

GONZÁLEZ, Felipe. "La OEA y los derechos humanos después del advenimiento de los gobiernos civiles: expectativas (in)satisfechas". Revista de derecho: División de Ciencias Jurídicas de la Universidad del Norte, 2001, $\mathrm{n}^{\circ}$ 1, p. 46-47. Disponível em: <http://w1.cejamericas. org/index.php/biblioteca/biblioteca-virtual/doc_view/2723-la-oea-ylos-derechos-humanos-despues-del-advenimiento-de-los-gobiernosciviles-expectativas-insatisfechas.html>

KELSEN, Hans. "As relações de sistema entre o direito interno e o direito internacional público". Revista de Direito Internacional, 2011, vol 8, n 22011.

NÚÑEZ POBLETE, Manuel. "Sobre la doctrina de margen de apreciación nacional. La experiencia latinoamericana confrontada y el thelos constitucional de una técnica de adjucación del Derecho Internacional de los Derechos Humanos". En: ACOSTA ALVARADO, P. e NÚÑEZ POBLETE, M. (Ed.). El margen de apreciación en el SIDH: proyecciones regionales y nacionales, México DF: Instituto de Investigaciones Jurídicas, 2012.

PORTO MACEDO Jr., Ronaldo. Freedom of Expression: What lessons should we learn from US experience? Disponível em: <https://www. law.yale.edu/system/files/area/center/kamel/sela16_macedo_cv_ eng_20160401.pdf>

SLAUGHTER, Anne-Marie. "A Global Community of Courts”. Harvard International Law Journal, 2003, vol 44, n 1, p. 191-219. 


\section{RESUMO BIOGRÁFICO}

Cláudio Cerqueira Bastos Netto é Mestre em Direito Internacional pela Universidade do Estado do Rio de Janeiro (UERJ). Bacharel em Direito pela UERJ. 